\title{
Estimation of risk factors affecting patients associated with bronchial asthma in Basrah, southern Iraq: Case-control observational study.
}

Falih Hmood Mezban $^{1}$ | Ihsan Edan Alsaimary $^{2^{*}}$

\begin{abstract}
This study aimed to describe some of the risk factors of asthma in Basra south in Iraq; The study showed that $(3,5)$ age group population were more affected with asthma $(27.9 \%)$ and the Females were more affected than males in group 2,3 and $5(6.4 \%, 15.7 \%$ and $14.7 \%)$ respectively compared to $(4.9 \%, 12.3 \%$ and 13.2$)$.In same group of male. While There were $(68.6 \%)$ of patients came from urban areas in comparison to $(31.4 \%)$ of cases who came from rural areas. The Smoking patients with positive (43.1\%). and well patients with animal contact positive their proportion was while $(49 \%)$. Seasonal asthma attack in male $(23.5 \%)$ more than female $(20.6 \%)$ the perennial asthma attach was recorded in male (29\%) more than female $(26.9 \%)$ in this study show Asthmatic patients with other allergy about $(15.7 \%)$ and with chronic diseases $\mathbf{( 3 1 . 9 \% )}$. The percentage of patients with positive family history were $39.2 \%$ of the cases.

Keywords: Demographic, risk factors, human bronchial asthma
\end{abstract}

\section{1 | INTRODUCTION}

A sthma is a complex respiratory disease in which genetic predisposition, environmental and immunological influences interfere with each other (Edwards, et al., 2012). It is considered one of the most prevalent chronic diseases, affecting approximately 300 million individuals (Masoli et al., 2004) and causing an estimated 250,000 deaths each year (Bateman et al., 2008). In addition, it is projected that by 2025 , the global asthma burden will rise by 100 million people due to a growing Westernized lifestyle and urbanization in developing countries (Masoli, et al., 2004). The 'hygiene theory' was originally attributed to an increase in the prevalence of allergic diseases, including asthma, indicating that decreased exposure to microbes during the first years of life plays a role in the development of allergic diseases (Strachan, 1989, 2000). While this theory is generally accepted, studies have shown that

Supplementary information The online version of this article (https://doi.org/10.15520/jmrhs.v4i1.304 ) contains supplementary material, which is available to authorized users.

Corresponding Author: Ihsan Edan Alsaimary University of Basrah, College of medicine,Department of Microbiology, Basrah, Iraq 
the increased incidence of asthma, rhinitis, or

Neurodermitis does not completely account for decreased microbial exposure (Mallol, 2008; Brooks et al.,2013 and Kramer et al., 2013). Asthma is a widespread illness globally and affects individuals of all ages, This condition usually occurs in infancy and is characterized by variable symptoms of wheeze, dyspnea, and chest tightness caused by air flow obstruction (fully reversible) (GINA, 2015 and Bisgaard \& Bonnelykke, 2010).

\section{2 | MATERIALS AND METHODS}

\section{Samples}

A total of (312) patients (149 males and 163 females) of various age groups were included in this Case -control study. The patient was examined, and diagnosed as asthma under supervision of the Physician.the study was carried out during a period from July 2018 to January 2020 .

\section{The grouping of patient}

Male\& Female patients were divided into five groups according to (Falk, 1993; Herd,et al.,1996 ; Nishioka,1996 and charman\&Williams,2002)

Group 1: 1- 11 years

Group 2: 12 - 20 years

Group 3: 21- 30 years

Group 4: 31 - 40 years

Group 5: above 40 years

\section{Control group}

A total of (204) healthy individual (81 males and 123 females) with out any features of asthma or any allergies to be compared with asthmatic patient in genetic and immunological studies.

\section{Demographics studies:}

Various demographic parameters were included in this study that includes:

1. Sex

2. Childhood environment

3. Rural and farming environment
4. Presence of furry animals during early childhood

5. Number of siblings

6. Urbanization

7. Smoking

\section{Statistical analysis}

Statistical analysis is done by using statistical package for social sciences(SPSS) software version 11, the chi square test, univariate and multivariate logistic regression analysis, the ANOVA analysis were applied for correlation between each study parameter, and the difference between two proportion by $\mathrm{T}$ - tests were used to assess the significance of difference between groups-Value less than 0.05 was considered as Statistically significance(S).P-value < 0.01 as highly significant(HS). and P-value $>0.001$ as extremely significant(ES).

\section{3 | RESULTS}

The studied age group includes all age groups from( $2-70$ ) years, the majority of asthmatic patients was recorded for age group $(21-30)$ years of both females and males(15.7) and (12.3\%) respectively while other factors has a majority as follows rural residency $(68.6 \%)$,No smoking(56.9\%), No presence of animals in the habitat in percentage (51\%).The results illustrate in table (1) There are a significant differences between most of Age groups, residency, smoking habit, and animal contact.

\section{4 | DISCUSSION:}

\section{Age groups:}

In the Asthmatic and control classes, Table (1) showed the mean ages. There was no substantial difference between the groups in terms of ages. The patient's age range was (2-41>) years and this was consistent with most AI research, such as Creticos, et al (1996). Regarding the age group, the highest percentage (27.9 percent) was (21-30) years old and 
TABLE 1: illustratedemographical characteristic of study subject.

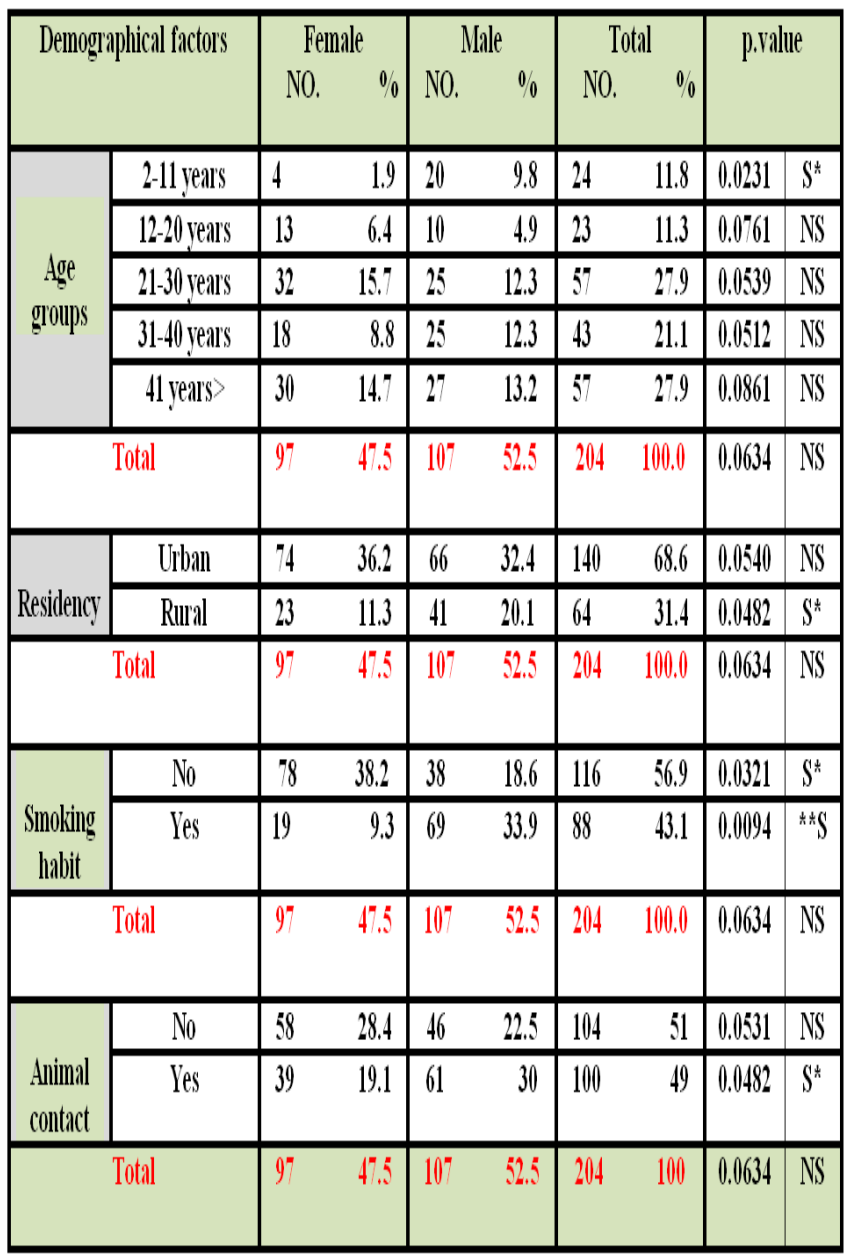

the lowest percentage (11.3 percent) was (12-20) years old, the researcher suggests that this outcome could have show higher prevalence of bronchial asthma in individuals from 21-26 years old. Hassan, (2009) endorsed this outcome;

DeMarco, et al., (2000) . This ages range was chosen, the wheal and flare not clearly appeared beyond these ages, moreover the degree of $\mathrm{IgE}$ is typically constant and stable at that age group. The level of $\operatorname{IgE}$ starts to increase from early childhood to hit the level of adults by the age (5-7) years and between the ages (10-14) years, before the age of 20, the level may be higher than that of adults. The IgE level may decrease slightly after the age of 60 years and be lower than the levels observed in adults (Winter et al., 2000). The study showed that asthma was more prevalent in age groups of $21-30>41$, so the results of age distribution in this study were in line with Pawar (2002).

\section{Sex distribution:}

males were more affected than Females as shown in table (1). The percentage of males was $52.5 \%$, whereas that of female was $47.5 \%$ throughout data analysis, the majority ( $52.5 \%$ ) were males, this indicates in majority of studies that asthma incidence were in males more than in females, and group (2-

11) significant only and group 21-30, 41> high asthmatic percentage the researcher believe this result may be due to a random sample for the study ,Prolong

exposure to allergic irritant in work places or while in crowded places or due to hormonal change between men and women. and this no agrees with study of Maddox and Schwartz, (2002) which stated that women aged 40 years have greater prevalence of asthma of the same age group. Also, Mingomataj et al., (2008). found that the percentage of females was $(62.6 \%)$ while that of male was $(37.4 \%)$. This sex difference may be due to female sex hormones. Nearly $40 \%$ of women report a premenstrual increase in asthma symptoms and also they have a regulatory role in $\beta 2$-adrenergic function, abnormal regulation ppear to be a possible mechanism for premenstrual asthma (Tan et al.,1997). This finding can be supported by the findings of Taha, and Ali, (2011). in Egypt for assessment therapeutic Guidelines effect for Bronchial Asthma on Adult Patients'

\section{Residence distribution}

According to their residence, the distribution of asthmatic patients in this study revealed that asthma was more prevalent in urban $(68.6 \%$ ) than rural $\operatorname{areas}(31.4 \%)$ as shown in table (1). Similar result was also produced by Kilpelainen et al.,(2000), the farm environment reduce risk of asthma in young adults in the presence or abscence of family history of atopy, besides people who lived in urban areas are in continuous and direct exposure to air pollution on a daily basis and were more likely to develop asthma. 
Eseverri et al., (1998). Studied the risk factors for development of asthma and among these risk factors, he found that all of the patients were from urban and urban-industrial areas. Rural residence was identified as the strongest protective factor against asthma in epidemiological studies and was likely associated with environmental exposure such as life style, diet, and hygiene ( Nicolou et al., 2005). Many epidemiological studies had showed evidence that migration from nonindustrial countries to industrial countries associated with increased risk of having asthma (Solé et al.,2007). Sensitization to pollen was higher in urban areas than rural areas despite pollen counts are higher in rural areas and this can be due to development of immunological tolerance to pollen allergens in rural areas or due to adjuvant effects of urban pollution. Riedles, et al., (2000) found out that exposure to stables and/or farm milk is protective only if prior to one year of age and so if the mother exposes to these factors during pregnancy, also it could be due to many factors, breast feeding, lack of immunization, in addition to the exposure to the products of milk. Laboratory animal studies indicated that air pollutants make mucus membranes of airways tracts become more permeable, leading to the development of allergic reactions Nicolai,(2002) ; Kauffman et al., (2002) found out that IgE levels are significantly lower in those who permanently live in the country and in particular in those who live for $>$ or $=10$ years, in addition, positive skin prick tests (SPT) were significantly less prevalent in those who permanently lived in the country. Majeed et al., (2008). found out that most of the asthmatic children lived in the urban areas of Hyderabad.

\section{Smoking habit}

The majority of participants were nonsmokers $(56.9 \%)$ while $(43.1 \%)$ were smokers, because the majority of samples from females , Regarding animal contact ,majority (49\%) of the study, the researcher believe this result may be explained due to animal production involves exposure to a variety of agent besides the animals themselves respiratory hazards that associate with animal production include inorganic dust from soil ,organic dust containing microorganisms, mycotoxin ,endotoxins , animal food particles, and allergens . These result confirmed by DM Umbach et,al,. (2003).

\section{5 | REFERENCES}

1. Alsaimary,I.(2006).Atopic dermatitis/ Eczyma Syndrome :A Molecular investigation of microbial super antigenicity with bacteriological , immunogical ,clinical ,hematological and histopathological studies. University of Basrah, college of science.

2. Al-Saimary Ihsan E .Prevalence of tuberculos is among patients in Basrah City . Journal Of Physics: Conf. Series 1294 (2019) 062087

3. Al-Saimary Ihsan E. Modes of allergy and total ige concentrations among various ages of basrah populations. International Research Journal Of Microbiology (Irjm) (Issn: 2141-5463) Vol. 2(8) Pp. 303-309, September 2011.

4. Alyasin, S., Karimi, M.H., Amin, R., Babaei, M. and Darougar, S.(2013). Interleukin-17 gene expression and serum levels in children with severe asthma. Iranian journal of immunology, 10(3):177-185

5. Amelink, M.; De Nijs, S.B.; De Groot, J.C.; Van Tilburg, P.M.; Van Spiegel, P.I.; Krouwels, F.H.; Lutter, R.; Zwinderman, A.H.; Weersink, E.J.; Ten Brinke, A.; Sterk, P.J. and Bel, E.H.(2013). Three phenotypes of adult-onset asthma Allergy: 68(5): 674-680.

6. Anand, K.S.S.; Ravi, G.N. and Narasimhaswamy, K.N. (2016). Study of pulmonary function test in allergic rhinitis patients of Sullia, Dakshina Kannada. Journal of Evolution of Medical and Dental Sciences.; 5(79):5867-5870.

7. Anderson, S. D.; Charlton, B.; Weiler, J. M.; Nichols, S.; Spector, S. L.; Pearlman, D. S., and Group, A. S. (2009). Comparison of mannitol and methacholine to predict exercise-induced bronchoconstriction and a clinical diagnosis of asthma. Respir. Research, 10(1), 4.

8. Beck, I.; Jochner, S.; Gilles, S.; McIntyre, M.; Buters, J. T. M.; Schmidt-Weber, C.; Behrendt, H.; Ring, J.; Menzel, A. and Traidl-Hoffmann, C. (2013). High environmental ozone levels 
lead to enhanced allergenicity of birch pollen. PloS. One, 8(11), 80147.

9. Bedada, G.B.; Heinrich, J.; Gotschi, T.; Downs, S.H.;Forsberg, B. and Jarvis, D.( 2007).Urban background particulate matter and allergic sensitization in adults of ECRHS II. Int. J .Hyg. Environ Health. ;210(6):691-700.

10. Beers, M.H. and Berkow, R. (1999).Bacteremia and septic shock. The Merck manual of diagnosis and therapy, 17th edition. Merck Research Laboratories, Whitehouse Station, New Jersey, pp.1143-1147.

11. Behrendt, H.; Kasche, A.; Von Eschenbach, C. E.; Risse, U.; Huss-Marp, J. and Ring, J. (2001). Secretion of proinflammatory eicosanoid-like substances precedes allergen release from pollen grains in the initiation of allergic sensitization. International Archives of Allergy and Immunology, 124(1-3), 121-125.

12. Bel, E. H. (2004).Clinical phenotypes of asthma. Current Opinion in Pulmonary Medicine, 10(1), 44-50.

13. Bel, E. H.; Sousa, A.; Fleming, L.; Bush, A.; Chung, K. F.; Versnel, J.; Wagener, A. H.; Wagers, S. S.; Sterk, P. J. and Compton, C. H. (2011).Unbiased Biomarkers for the Prediction of Respiratory Disease Outcome Consortium CG. Diagnosis and definition of severe refractory asthma: an international consensus statement from the Innovative Medicine Initiative (IMI). Thorax, 66(10), 910-917.
14. Chen, Z. and O'Shea, J.J.( 2008).Regulation of IL-17 production in human lymphocytes. Cytokine.; 41(2):71-78.

15. Chernoff, A.E.; Granowitz, E.V.; Shapiro, L.(1995). A randomized, controlled trial of IL-10 in humans. Inhibition of inflammatory cytokine production and immune responses. J. Immunol.; 154: 5492-5499.

16. Cho, S.H., Stanciu, L.A., Holgate, S.T. and Johnston, S.L.(2005).Increased interleukin-4, interleukin-5, and interferon- $\gamma$ in airway CD4+ and CD8+ $\mathrm{T}$ cells in atopic asthma. American journal of respiratory and critical care medicine.; 171(3):224-230.

17. Chung, K.F.; Wenzel, S.E.; Brozek, J.L.; Bush, A.; Castro, M.; Sterk, P.J.; Adcock, I.M.; Bateman, E.D.; Bel, E.H.; Bleecker, E.R.; Boulet, L.P.; Brightling, C.; Chanez, P.; Dahlen, S.E.; Djukanovic, R.; Frey, U.; Gaga, M.; Gibson, P.; Hamid, Q.; Jajour, N.N.; Mauad, T.; Sorkness, R.L. and Teague, W.G.(2014).International ERS/ATS guidelines on definition, evaluation and treatment of severe asthma. Eur. Respir. J.: 43(2): 343-373.

How to cite this article: F.H.M., I.E.A. Estimation of risk factors affecting patients associated with bronchial asthma in Basrah, southern Iraq: Case-control observational study.. Journal of Medical Research and Health Sciences. 2021;1146-1150. https://doi.org/10.15520/jmrhs.v4i1.304 